\title{
Study on recovery time of a superconducting fault current limiter with adjustable trigger current level
}

\section{AUTHOR(S):}

Shirai, Y; Fujikawa, K; Kitagawa, T; Shiotsu, M; Hatta, H; Muroya, S; Nitta, T

\section{CITATION:}

Shirai, Y ... [et al]. Study on recovery time of a superconducting fault current limiter with adjustable trigger current level. IEEE TRANSACTIONS ON APPLIED SUPERCONDUCTIVITY 2001, 11(1): 2086-2089

\section{ISSUE DATE:}

2001-03

URL:

http://hdl.handle.net/2433/50254

\section{RIGHT:}

(c)2001 IEEE. Personal use of this material is permitted. However, permission to reprint/republish this material for advertising or promotional purposes or for creating new collective works for resale or redistribution to servers or lists, or to reuse any copyrighted component of this work in other works must be obtained from the IEEE. 


\title{
Study on Recovery Time of a Superconducting Fault Current Limiter with Adjustable Trigger Current Level
}

\author{
Yasuyuki Shirai , Kazuhiro Fujikawa, Tomoyuki Kitagawa, Masahiro Shiotsu, \\ Hiroyuki Hatta, Shiniti Muroya, and Tanzo Nitta
}

\begin{abstract}
The recovery time of a transformer type SCFCL (Superconducting Fault Current Limiter) with adjustable trigger current level, is studied experimentally. The recovery time is defined as the required time of zero current period of SCFCL for recovery from its current limiting mode to its waiting mode. A trial SCFCL, which was designed and made, is tested to measure the recovery time with various fault time. The experimental results show that the recovery time depends on the fault time. When the fault time is longer than $200 \mathrm{~ms}$, the recovery time becomes shorter and approaches a certain value (a few ten $\mathrm{ms}$ ) as the fault time is longer.
\end{abstract}

Index Terms - Superconducting fault current limiters (SCFCLs), trigger current level, recovery time, fault time

\section{INTRODUCTION}

GUPERCONDUCTING fault current limiters (SCFCLs) $\mathcal{N}$ are expected to improve reliability of power systems. Many studies have been done on the SCFCL of various types [1]-[3]. We carried out fault analyses of power system that include SCFCL's. The results of the fault analyses show that accuracy of the trigger current level, at which the SCFCL starts to limit the fault current, should be within a few ten percent in some system configurations [4]. In general, the trigger current level of the SCFCL is determined by the super-normal transition current of the superconducting coil. It is not so easy, however, to manufacture superconducting coils with several percent accuracy of the super-normal transition current.

Therefore, we proposed an SCFCL with adjustable trigger current level. A model was designed and made [5]. The proposed SCFCL consists of two superconducting coils coupled coaxially without an iron core. The inner coil (primary coil) is connected to power line. The outer coil (secondary coil) is short-circuited. Basic tests on the SCFCL were carried out. It was confirmed that the trigger current level can be calibrated by sliding the secondary coil and can be changed by replacing only the secondary coil of another specification [6].

Joule heat loss of the transformer type SCFCL while it suppresses the fault current (the current limiting mode)

Manuscript received September 18, 2000. This work was supported in part by the Japan Society for the Promotion of Science under Project No. JSPS-RFTF97P01004.

Y. Shirai, K. Fujikawa, T. Kitagawa and M. Shiotsu are with Department of Energy Science and Technology, Kyoto University, Yoshida-Honmachi, Sakyo-ku, Kyoto, 606-8501 Japan. Y. Shirai's E-mail: shirai@energy.kyoto-u.ac.jp

H. Hatta, S. Muroya and T. Nitta are with Department of Electrical Engineering, the University of Tokyo, 7-3-1, Hongo, Bunkyo-ku, Tokyo, 113-8656 Japan. T. Nitta's E-mail: nitta@asc.t.u-tokyo.ac.jp. was measured. It was expected that the recovery time of the proposed type SCFCL is short [7].

In this paper, the recovery time of the trial SCFCL was measured with various fault time.

\section{Superconducting Fault CuRrent Limiter with Adjustable Trigger Current Level}

\section{A. Principle}

The proposed SCFCL [5]-[7], whose cross section is shown in Fig. 1, consists of two superconducting coils coupled coaxially. The inner (primary) coil will be connected to a power line. The outer (secondary) coil is shortcircuited. Fig. 1 shows that the secondary coil is slided with small slide distance $\mathrm{D}$ in order to calibrate the trigger current level without changing the super-normal transition current of the secondary wire. In the waiting mode, both superconducting coils are in the superconducting state. When the fault current flowing through the SCFCL exceeds the trigger current level, the super-normal transition occurs only at the secondary wire. The fault current is limited mainly by the reactance of the primary coil.

\section{B. Trial SCFCL}

A trial SCFCL of the proposed type, whose specifications are listed in Table I, was designed and made [5]. The

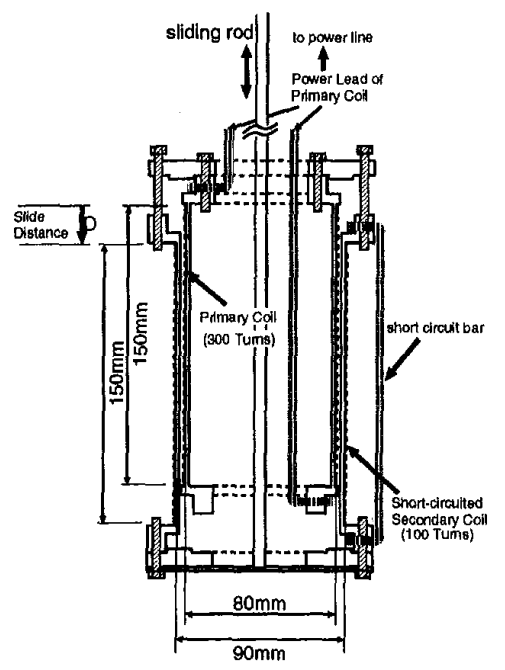

Fig. 1. Cross sectional view of the trial superconducting fault current limiter with the secondary coil slided by a slide distance $D$. 
TABLE I

Specifications of THE TRIAL SCFCL

\begin{tabular}{|c|c|c|}
\hline Primary coil & $\begin{array}{l}\text { Height } \\
\text { Inner diameter } \\
\text { Turns }\end{array}$ & $\begin{array}{l}150 \mathrm{~mm} \\
80 \mathrm{~mm} \\
300\end{array}$ \\
\hline Secondary coil & $\begin{array}{l}\text { Height } \\
\text { Inner diameter } \\
\text { Turns }\end{array}$ & $\begin{array}{l}150 \mathrm{~mm} \\
90 \mathrm{~mm} \\
100\end{array}$ \\
\hline Inductance (design) & $\begin{array}{l}L_{1} \text { (primary) } \\
L_{2} \text { (secondary) }\end{array}$ & $\begin{array}{l}2.90 \mathrm{mH} \\
0.44 \mathrm{mH}\end{array}$ \\
\hline coupling coefficient $k$ & (slide $0 \mathrm{~mm}$ ) & 0.89 \\
\hline
\end{tabular}

TABLE II

SPECIFICATIONS OF SUPERCONDUCTING WiRE

\begin{tabular}{|c|c|c|}
\hline Items & & Specification \\
\hline Strand & $\begin{array}{l}\text { Structure } \\
\text { Diameter of strand } \\
\text { Material of matrix } \\
\text { Material of filament } \\
\text { Diameter of filament } \\
\text { Number of filament } \\
\text { Twist pitch } \\
\text { Twist direction } \\
\text { Insulation }\end{array}$ & $\begin{array}{l}\text { Multi-filament } \\
0.126 \mathrm{~mm} \\
\mathrm{Cu}-30 \% \mathrm{Ni} \\
\text { (CuNi:NbTi=4.3:1) } \\
\text { NbTi } \\
0.08 \mu \mathrm{m} \\
441,575 \\
0.7 \mathrm{~mm} \\
\text { Clockwise(S) } \\
\text { None }\end{array}$ \\
\hline Twisted wire & $\begin{array}{l}\text { Structure } \\
\text { Material of core } \\
\text { Diameter of core } \\
\text { Twist pitch } \\
\text { Twist direction }\end{array}$ & $\begin{array}{l}6 \text { Strands+Core } \\
\mathrm{Cu}-30 \% \mathrm{Ni} \\
\sim 0.16 \mathrm{~mm} \\
2 \mathrm{~mm} \\
\text { Counterclockwise(Z) }\end{array}$ \\
\hline Characteristics & $\begin{array}{l}\text { Critical current } \\
\left(I_{q}\right) \\
\text { Normal resistance }\end{array}$ & $\begin{array}{l}\sim 150 \mathrm{~A} \\
(\text { at } 4.2 \mathrm{~K}, 0 \mathrm{~T}) \\
\sim 3.18 \Omega / \mathrm{m}\end{array}$ \\
\hline
\end{tabular}

SCFCL has no magnetic core. The specifications of the superconducting wire is shown in Table II.

\section{Impedance of $S C F C L$}

The resistive and the inductive components $R_{\mathrm{FCL}}, X_{\mathrm{FCL}}$ of the impedance $Z_{\mathrm{FCL}}$ of the trial SCFCL are given as a function of the resistance $R_{2}$ of the secondary coil as shown in Fig. 2 [7]. The inductive component $X_{\mathrm{FCL}}$ increases rapidly as $R_{2}$ increases. The resistive component $R_{\mathrm{FCL}}$ has a peak value $R_{\mathrm{FCL} 0}=\frac{1}{2} \omega k^{2} L_{1}$ at the resistance $R_{2}=\omega L_{2}$ and decreases as $R_{2}$ increases, where $L_{1}, L_{2}$ is inductance of the primary coil and the secondary coil, respectively, $k$ is the coupling coefficient and $\omega$ is the angular frequency of the power source. It is one of the important advantages of the SCFCL that the fault current is limited by the inductive component $X_{\mathrm{FCL}}$, which is almost constant for a wide range of the resistance $R_{2}$. Measured resistance $R_{2}$ proved that only a part of the secondary wire is in the normal state. It was confirmed that the normal zone length, which is proportional to the resistance $R_{2}$, and the secondary coil current are determined to keep the heat balance between joule heat generated in the wire and heat flow to liquid helium at the surface of the wire in a ther-

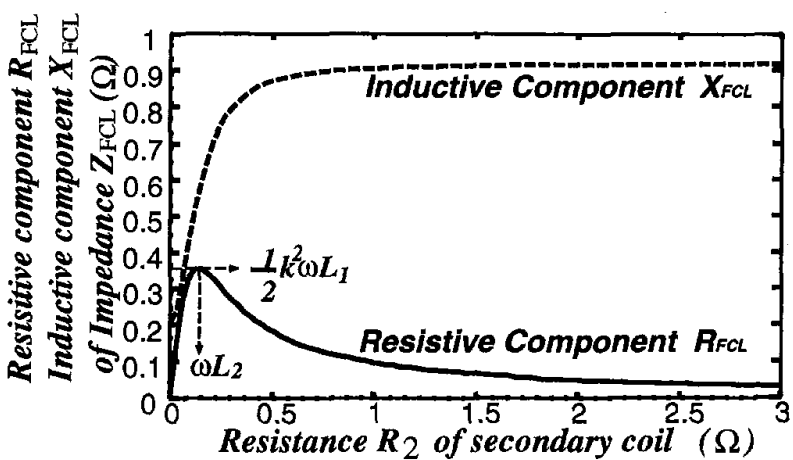

Fig. 2. Resistive and inductive component of impedance $Z_{\text {FCL }}$.

mal equilibrium state [7]. Therefore, the joule heat loss in the current limiting mode is small and the recovery time is expected to be short.

\section{EXPERIMENT}

\section{A. Experimental Circuit}

An experimental circuit of the trial SCFCL is shown in Fig. 3. Two reactors "a" and " $\mathrm{b}$ " and the SCFCL are connected in series to the $\mathrm{AC}$ power source $(50 \mathrm{~Hz})$ through a variable voltage transformer (slidac). A short-circuit switch SW2 (MC:Magnetic Controlled Contact) is connected in parallel to the reactor " $b$ " to simulate a fault. The inductance $L_{a}$ and $L_{b}$ of the reactors are $2.13 \mathrm{mH}$ and 6.40 $\mathrm{mH}$, respectively. A switch SW1(MC) is used to remove or reconnect the reactors and the SCFCL from or to the $A C$ power source.

The current $i_{\mathrm{FCL}}$ of the SCFCL (the circuit current), the voltage $v_{F C L}$ of the SCFCL, the voltage $v_{\mathrm{SL}}$ of the output voltage of the slidac and the voltage $v_{\mathrm{SW}}$ across the reactor " $b$ " were measured.

\section{B. Test procedure}

The switching sequence of the switches SW1 and SW2 is shown in Fig. 4. The test procedure is described as follows.

1. The switch SW2 is open, the switch SW1 is closed. The slide distance $D$ is set to be $0 \mathrm{~mm}$. The SCFCL is in the waiting mode (low impedance).

2. The switch SW2 is closed to simulate a fault. When the current $i_{\mathrm{FCL}}$ at the fault reaches the trigger cur-

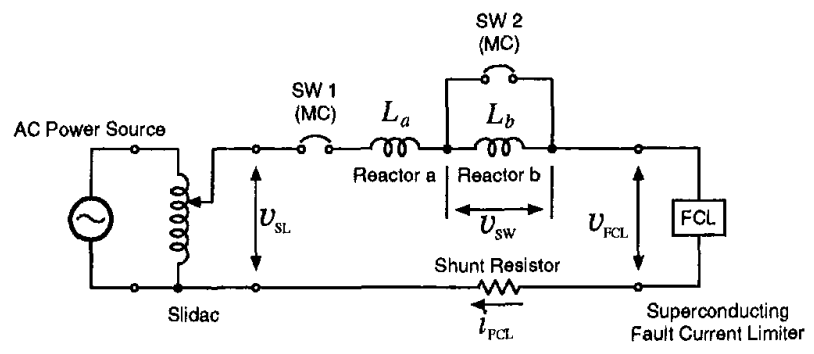

Fig. 3. Circuit for the tests on the trial SCFCI 


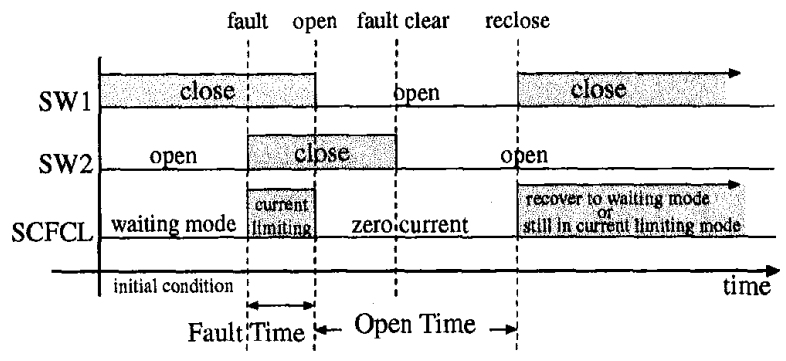

Fig. 4. Switching sequence of SW1, SW2 and "Fault Time" and "Open Time".

rent level, the super-normal transition occurs in the secondary wire. The SCFCL changes from the waiting mode to the current limiting mode (high impedance).

3. The switch SW1 is opened to remove the fault circuit and the SCFCL from the AC power source. "Fault, Time" is defined as the time while the fault current flows through the circuit.

4. The switch SW2 is opened to clear the fault while the switch SW1 is opened.

5. The switch SW1 is reclosed to reconnect the SCFCL and the reactors to the power source. "Open Time" is defined as the time while the SCFCL is disconnected from the power source, that is, the zero current period of the SCFCL.

The switches SW1 and SW2 were controlled by a sequence controller which can changes the time intervals of the switching sequence. The tests were carried out taking "Fault Time" and "Open Time" as parameters.

\section{Experimental Results}

One of the experimental results is shown in Fig. 5. The figure shows the wave forms of the current $i_{\mathrm{FCL}}$ of the SCFCL, the voltage $v_{\mathrm{FCL}}$ across the SCFCL, the voltage $v_{\mathrm{SW}} 2$ across the SW2 and the output voltage $v_{\mathrm{SL}}$ of the slidac from top to bottom. For the initial conditions, the voltage $v_{\mathrm{SL}}$ was set to be $58.1 \mathrm{Vrms}$ and the initial current of the circuit was 20 Arms.

The switch SW2 was closed (fault) at time $=0 \mathrm{~s}$, and the fault current began to flow through the SCFCL. After about $3 \mathrm{~ms}$, the fault current reached $42 \mathrm{~A}$ (the trigger current level of the SCFCL) and the SCFCL began to limit the fault current to be 36.8 Arms (current limiting mode). The fault current would be 63.4 Arms if the SCFCL would not limit the current. The SCFCL was removed from the circuit at $167 \mathrm{~ms}$ (Fault Time) after the fault occurrence. The current through the SCFCL became zero. SW2 was opened (fault clear) about $20 \mathrm{~ms}$ after the removal, but this event did not appear in the wave forms. The reactors and SCFCL were reconnected to the power source at time $=613$ ms ("Open Time" is $446 \mathrm{~ms}$ ). The voltages and current returned to be in the same condition before the fault in this test case. The secondary wire returned to be in the superconducting state, and the SCFCL recovered to the waiting mode successfully.

The tests were carried out in the same manner as described above with various "Open Time" for various "Fault Time". It was checked whether the SCFCL was still in the current limiting mode or not, after the reclosure of the cir-
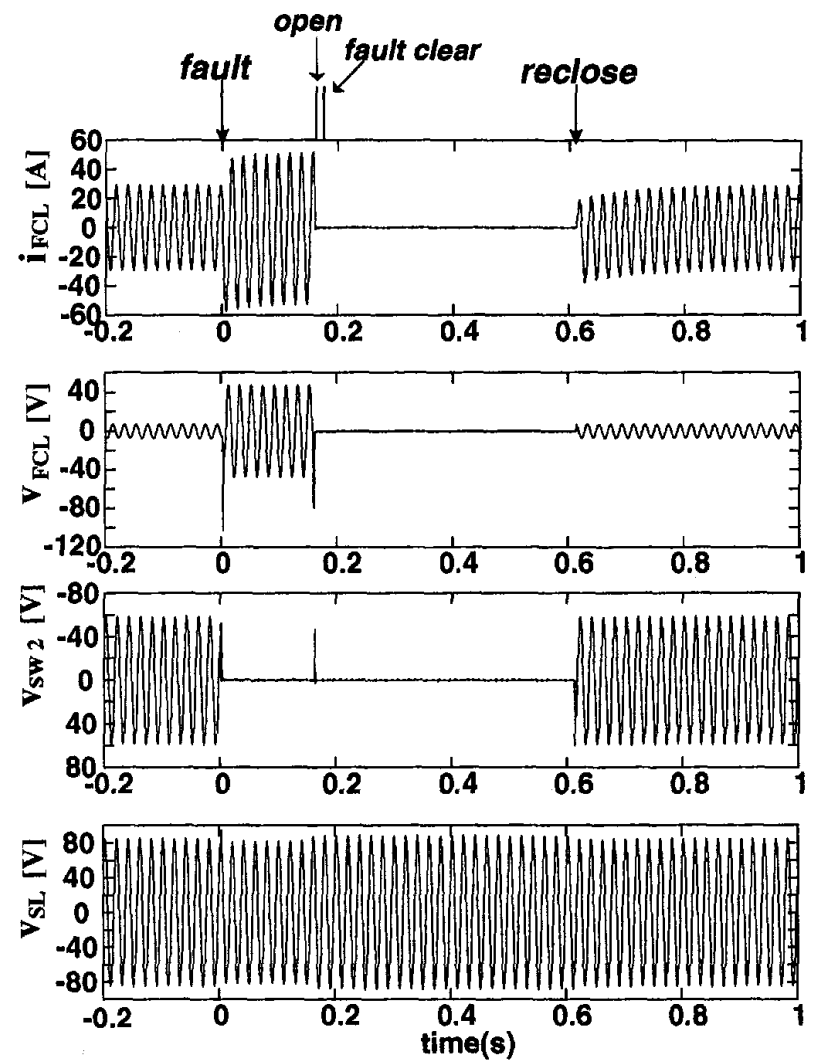

Fig. 5. Wave forms of voltages and current during the test procedure. (Experimental result)

cuit. The experimental results are shown in Fig. 6, where the round sign indicates that the SCFCL recovered to the waiting mode successfully, and the cross indicates that the SCFCL failed to recover to the waiting mode.

\section{Discussion}

Fig. 6 shows that the "Recovery Time" which is defined as the required "Open Time" for the SCFCL to recover to its waiting mode, is depend on the "Fault Time". The plane of "Open Time" and "Fault Time" is roughly divided to two areas of the successful recovery cases and the recovery failure cases by the solid line in Fig. 6. Therefore, the "Recovery Time" is approximately expressed by the solid line.

The "Recovery Time" has a peak value of about 380 ms with "Fault Time" of about $200 \mathrm{~ms}$. It was pointed out that the SCFCL can recover to its waiting mode with "Open Time" of more than $380 \mathrm{~ms}$ for any "Fault Time". The required "Open Time" of $380 \mathrm{~ms}$, which is shorter than 20 cycles of the AC power source, is shorter than a typical reclosing time of a circuit breaker in Japan.

While the "Fault Time" is shorter than about $200 \mathrm{~ms}$, the "Recovery Time" becomes longer as the "Fault Time" is longer. However, when the "Fault Time" is longer than about $200 \mathrm{~ms}$, the "Recovery Time" decreases gradually and approaches to a certain value (a few ten ms) as the 


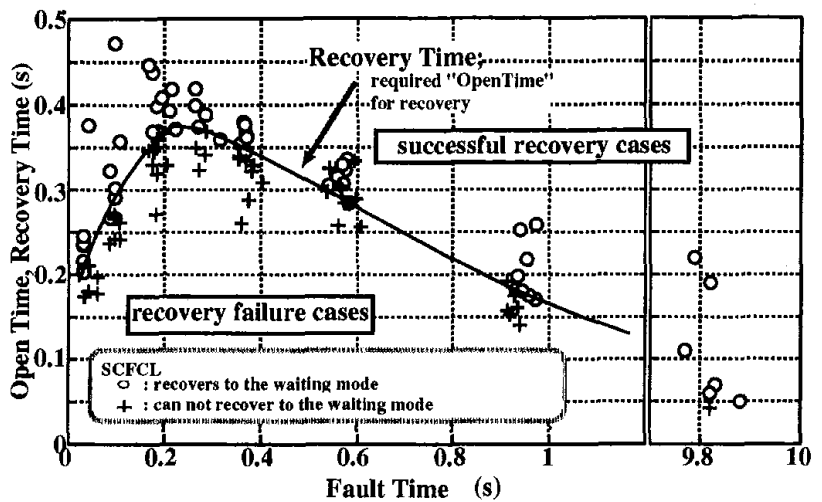

Fig. 6. Recovery Time against the Fault Time.

"Fault Time" is longer. The "Recovery Time" is about 50 ms when the "Fault Time" is almost $10 \mathrm{~s}$.

Because there is no heat generating power source during the period of "Open Time" in the SCFCL, the superconducting wire of the secondary coil, a part of which has resistivity (that is, a normal zone of the superconducting wire), is cooled down by the liquid helium and the temperature of the normal zone decreases towards the temperature 4.2 $\mathrm{K}$ of liquid helium. The normal zone disappears and the SCFCL recovers to its waiting mode after a certain time ("Recovery Time"). It can be assumed that the "Recovery Time" depends on the temperature distribution profile along the superconducting wire at the removal of the SCFCL from the power source. The recovery time is longer, as the temperature of the normal zone of the secondary wire is higher and the normal zone length is longer. As a result, the temperature change with time of the normal zone can be discussed by the "Recovery Time" for the "Fault Time" shown in Fig. 6.

At the beginning of the current limiting mode, the joule heat is generated locally around the position of the wire where the super-normal transition occurred at the first. The temperature of the normal zone rises up. The normal zone of the superconducting wire spreads along the wire, and the resistance of the secondary coil increases immediately. The current of the secondary coil is reduced, and the generated joule heat decreases immediately. Therefore, when the "Fault Time" is more than $200 \mathrm{~ms}$, the temperature rise is stopped and the temperature begins to fall.

It was already reported [7] that, after a sufficient time from the fault occurrence, the current of the secondary winding becomes almost equal to the minimum propagation current of the superconducting wire. Then, it can be assumed that the temperature distribution profile of the normal zone is almost uniform along the superconducting wire. The joule heat loss per unit length at the normal zone balances with the heat flux at the surface of the normal zone of the wire (thermally equilibrium state). Therefore, the "Recovery Time" is quite short.

It is an important advantage of this type of SCFCL that the temperature rise of the superconducting wire is suppressed to a certain value, even if the fault current continues to flow through the SCFCL due to an operation failure of a circuit breaker. In other words, the SCFCL can be applied without circuit breakers, if the SCFCL is designed to suppress the fault current to a sufficiently small value.

\section{CONCLUSions}

The "Recovery Time" (the required zero current time of the SCFCL for recovery from the current limiting mode to the waiting mode) was measured for various "Fault Time" (the time while the fault current flows through the SCFCL) using the trial SCFCL with adjustable trigger current level. The results obtained are as follows.

- It was confirmed that the "Recovery Time" depends on the "Fault Time".

- The "Recovery Time" has a peak value of about $380 \mathrm{~ms}$ with "Fault Time" of about $200 \mathrm{~ms}$. It was pointed out that the SCFCL can recover to its waiting mode with the zero current time of longer than $380 \mathrm{~ms}$ for any "Fault Time", which is shorter than a typical reclosing time of a circuit breaker in Japan.

- When the "Fault Time" is longer than about 200 ms, the "Recovery Time" decreases gradually and approaches to a certain value as the "Fault Time" is larger.

- The temperature rise of the superconducting wire is suppressed to a certain value, even if the fault current continues to flow through the SCFCL due to an operation failure of a circuit breaker. This is one of the important advantages of this type of SCFCL.

\section{ACKNOWLEDGEMENT}

The authors would like to thank Mr. Masakuni Chiba and other members of the laboratory for their great help in the experiments.

\section{REFERENCES}

[1] T. Hara, T. Okuma, T. Yamamoto, D. Ito, K. Tasaki and K. Tsurunaga, "Development of a new $6.6 \mathrm{kV} / 1500 \mathrm{~A}$ class superconducting fault current limiter for electric power systems," IEEE Trans. on Power Delivery, vol. 8, No. 1, pp. 182-192, January 1993.

[2] M. Ichikawa and M. Okazaki, "A magnetic shielding type superconducting fault current limiter using a Bi2212 thick film cylinder," IEEE Trans. on Applied Supenconductivity, vol. 5, No. 2, pp. 1067-1070, June 1995.

[3] B. Gromoll, G. Ries, W. Schmidt, H.-P. Krämer, P. Kummeth and H.-W. Neumüller, "Resistive current limiter with YBCO films," IEEE Trans. on Applied Superconductivity, vol. 7, No. 2, pp. 828-831, June 1997 .

[4] T. Nitta, K. Fujikawa and Y. Shirai, "Studies on specification of superconducting fault current limiter in double circuit transmission line," 1996 National Convention of I.E.E. Japan, Tokyo, March 1996, No. 1210, (in Japanese).

[5] K. Fujikawa, Y. Shirai, T. Nishikawa, T. Nitta, M. Fukunishi and T. Shibata, "Experimental study on superconducting fault current limiter with adjustable trigger current level," Proceedings of 15th International Conference on Magnet Technology (MT-15), (Beijing, October 1997), pp. 571-574, September 1998, Science Press.

[6] K. Fujikawa, Y. Shirai, T. Nitta, K. Hagiwara and T. Shibata, "Experimental study on adjustability of superconducting fault current limiter with adjustable trigger current level," IEEE Trans. on Applied Superconductivity, vol. 9, No. 2, pp. 13511354, June 1999

[7] Y. Shirai, K. Fujikawa, T. Nitta, K. Hagiwara and T. Shibata, "Recovery characteristics of fault current limiter with adjustable trigger current level," IEEE Trans. on Applied Superconductivity, vol. 9, No. 2, pp. 1381-1384, June 1999. 